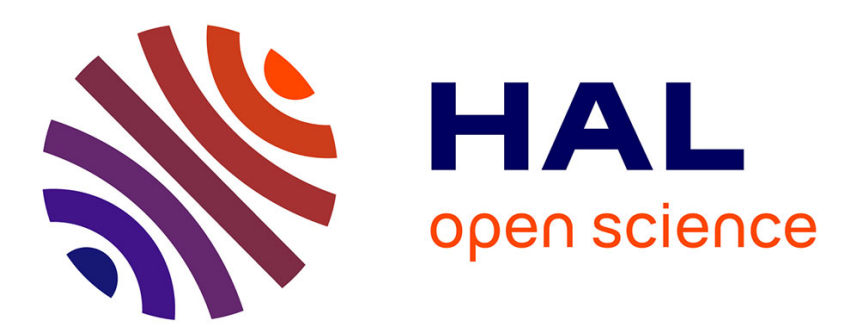

\title{
Shielding Effectiveness of Perforated Screens Through an Inverse Problem-Based Resolution
}

Imed Briki, Lionel Pichon, Jaleleddine Ben Hadj Slama

\section{To cite this version:}

Imed Briki, Lionel Pichon, Jaleleddine Ben Hadj Slama. Shielding Effectiveness of Perforated Screens Through an Inverse Problem-Based Resolution. IEEE Transactions on Magnetics, 2016, 52 (3), pp.8000604. 10.1109/TMAG.2015.2495185 . hal-01345635

\section{HAL Id: hal-01345635 \\ https://hal.science/hal-01345635}

Submitted on 23 Aug 2020

HAL is a multi-disciplinary open access archive for the deposit and dissemination of scientific research documents, whether they are published or not. The documents may come from teaching and research institutions in France or abroad, or from public or private research centers.
L'archive ouverte pluridisciplinaire HAL, est destinée au dépôt et à la diffusion de documents scientifiques de niveau recherche, publiés ou non, émanant des établissements d'enseignement et de recherche français ou étrangers, des laboratoires publics ou privés. 


\title{
Shielding Effectiveness of Perforated Screens through an Inverse Problem-based Resolution
}

\author{
Imed Briki ${ }^{1}$, Lionel Pichon ${ }^{2}$, and Jalel Ben Hadj Slama ${ }^{1}$ \\ ${ }^{1}$ University of Sousse, National engineering school (ENISo), Technopole of Sousse, 4054 Sousse, Tunisia \\ ${ }^{2}$ Group of electrical engineering - Paris, CentraleSupélec, CNRS, Université Paris-Sud, Université Pierre et Marie Curie; \\ Plateau de Moulon, F-91192 Gif-sur-Yvette, France
}

\begin{abstract}
This paper shows that the radiated fields from perforated plane shields excited by a circular loop are the same than those produced by one or several magnetic dipoles located on the plane of the apertures. The way to derive this equivalent model is based on an inverse problem using optimization methods and near-field calculation (method of moments) or measurements. The proposed approach allows to evaluate the shielding effectiveness of the perforated screens. All results are compared with experimental values to check the validation. Such equivalent models could be used to avoid meshing screens in case a 3-D problem involving an enclosure with arrays of apertures or to simplify EMC analysis of power electronic devices having shielded enclosures.
\end{abstract}

Index Terms - Electromagnetic compatibility, apertures, optimization method, inverse problem, shielding effectiveness.

\section{INTRODUCTION}

$\mathrm{T}$ HERE is a growing need to calculate the shielding effectiveness of enclosures including electronic circuits in order to evaluate the radiated fields in electromagnetic compatibility problems. The evaluation of the shielding effectiveness for planar structures of infinite extend can be performed by analytical solutions of Maxwell's equations [1,2]. However in realistic configurations enclosures have generally some apertures or arrays of holes dedicated to visibility, airflow or access to interior components. To model the coupling of electromagnetic perturbations with such structures conventional 3D analysis method could be used like in $[3,4]$. The discretization of such screens using standard three dimensional techniques based on volume meshes (finite elements, finite differences) may lead to unwanted increase of memory and computational time due to a refined mesh around the multiple holes.

The analysis of the coupling between a plane wave and apertures can be addressed analytically as in [1]. The problem of shielding in the near-field has received much less attention so far. In simplified geometries analytical solutions become available. For example a 2D magneto-static case is solved in [5]. Frequency problems have been addressed analytically for an electric dipole as the source in [6,7] and a circular loop as the source in [8]. However in these two cases the solution is only valid for periodic screens of infinite extent and cannot be used for realistic problems like shielding enclosures allowing protection against electromagnetic interferences.

In power electronics, where higher frequencies are below several hundred of $\mathrm{MHz}$, an efficient characterization of the radiated fields in free space can be performed using equivalent

Manuscript received April 1, 2015; revised May 15, 2015 and June 1, 2015; accepted July 1, 2015. Date of publication July 10, 2015; date of current version July 31, 2015. Corresponding author: L. Pichon (e-mail: lionel.pichon@geeps.centralesupelec.fr).

Color versions of one or more of the figures in this paper are available online at http://ieeexplore.ieee.org.

Digital Object Identifier (inserted by IEEE). dipoles. With such approach a set of electric and/or magnetic dipoles can replace the practical system while giving the same radiated near field. [9-11]. The idea is to avoid a fine description of the components (printed circuit board, traces etc.) that would lead to intractable modeling problems using conventional meshing methods. Such an approach provides a powerful tool. However in many industrial cases the electronic equipments are located in shielding enclosures and the radiation arises from the apertures.

To take into account the radiated field through apertures in near field, it is proposed in this work to replace the whole screen by one or several equivalent dipoles. The parameters of the dipoles are evaluated via an inverse problem based on an optimization method and using magnetic near-field data. The optimization method combines the genetic algorithm and the pattern search. In this paper a circular loop has been chosen as a source. This choice wants to illustrate the radiation of power electronic systems where the major sources arise from current paths along traces of power circuit boards.

\section{STUDIED CONFIGURATIONS}

The considered plane screens are made from copper and present different forms of perforations as shown in figure 1 . The shield S1 presents 9 round apertures (diameter $7 \mathrm{~mm}$ ). The shield S2 has 25 square apertures (side $5 \mathrm{~mm}$ ). The shield S3 has two ranges of 6 slots ( $8 \mathrm{~mm} \times 2 \mathrm{~mm})$. The shield S4 has 60 apertures with dimensions $4 \mathrm{~mm} \times 2 \mathrm{~mm}$. The shield S5 has 40 rectangular apertures with dimensions $4 \mathrm{~mm} \times 2 \mathrm{~mm}$. All copper shield products are square of $32 \mathrm{~mm}$ as length of the side and $35.10-3 \mathrm{~mm}$ as thickness.

The goal is to evaluate the shielding effectiveness given by:

$$
S E=20 \log \left(\frac{\left|\vec{H}_{i}\right|}{\left|\vec{H}_{t}\right|}\right)
$$

where $H_{i}$ is the magnetic field without the shield and $H_{t}$ the magnetic field with the shield.

To evaluate SE two consecutive near-field evaluations are 
necessary, with and without the shield, respectively. Here a 2Dscan method is performed at $470 \mathrm{MHz}$ as the excitation frequency. The radiating loop with radius $5 \mathrm{~mm}$ is located parallel to the screen, at a distance $\mathrm{z}=1.5 \mathrm{~mm}$ (Fig.2).

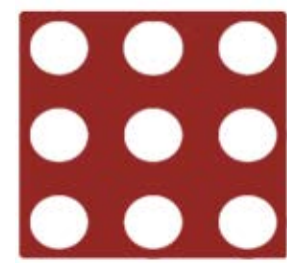

S1

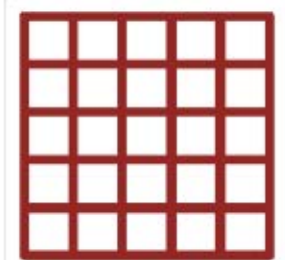

S2

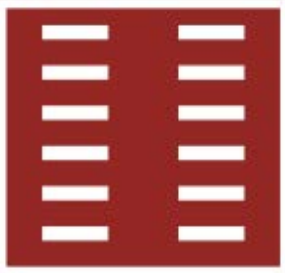

S3

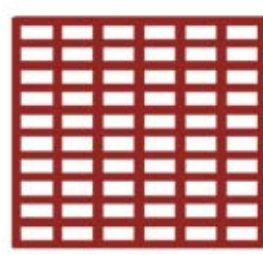

S4

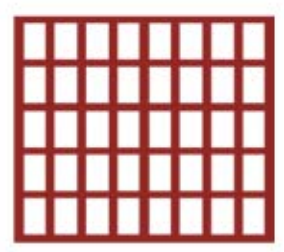

S5

Fig. 1. Geometry of metallic screens

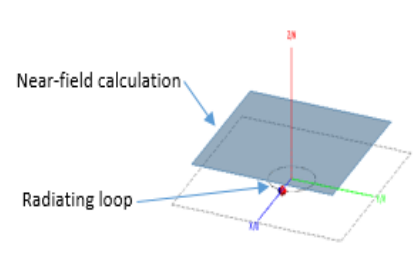

without shield

with shield

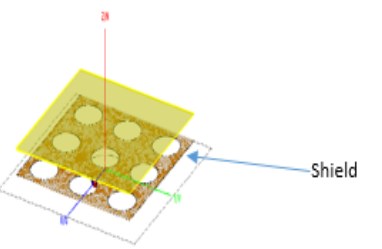

with shield

The near-field data is used to validate the shielding effectiveness prediction and to solve the inverse problem detailed in the following section.

\section{INVERSE PROBLEM}

\section{A. Problem definition and algorithms}

A magnetic dipole located at position $\vec{s}$ with a radius $a$ and a current $\mathrm{I}$ in the wire, is characterized by its magnetic moment :

$$
\overrightarrow{\mathrm{M}=\mathrm{I} \cdot \mathrm{s}=\mathrm{I} \cdot \pi \cdot \mathrm{a}^{2} \cdot \overrightarrow{\mathrm{u}_{\mathrm{M}}}}
$$

where $\mathrm{u}_{\mathrm{M}}$ is the unit orientation vector of the magnetic moment.

The magnetic field radiated by one dipole is given by :

$$
\overrightarrow{\mathrm{H}} \bmod \left(\overrightarrow{\mathrm{R}}_{\mathrm{m}}^{\rightarrow} \mathrm{k}\right)=\mathrm{F}\left(\mathrm{R}_{\mathrm{m}}^{\rightarrow}, \mathrm{k}\right) \overrightarrow{\mathrm{M}}-\mathrm{G}\left(\overrightarrow{\mathrm{R}}_{\mathrm{m}}^{\rightarrow}, \mathrm{k}\right)\left(\begin{array}{l}
\overrightarrow{\mathrm{M}}_{\mathrm{m}} \mathrm{R}_{\mathrm{m}} \\
\mathrm{R}_{\mathrm{m}}
\end{array}\right.
$$

where $k=\frac{2 \pi}{\lambda}$ is the wave number ( $\lambda$ is the wavelength) and ${ }_{\mathrm{m}}^{\mathrm{R}_{\mathrm{m}}}=\overrightarrow{\mathrm{r}-\mathrm{s}_{\mathrm{m}}}$ with ${ }_{\mathrm{m}}^{\rightarrow}$ the position vector of the magnetic dipole and $\vec{r}$ is the vector defining the position of the observation point,

$$
\begin{aligned}
& F\left(\vec{R}_{m}, k\right)=\frac{k^{2}}{4 \pi}\left(1+j \frac{1}{k_{m}}-\frac{1}{\left.k_{m}\right)^{2}}\right) \cdot \frac{e^{j k R}}{R_{m}} \\
& G\left(\vec{R}_{m}, k\right)=\frac{k^{2}}{4 \pi}\left(1+\frac{3 j}{k R}-\frac{3}{\left.\left.k_{m}\right)_{m}\right)^{2}}\right) \cdot \frac{e^{j k R}}{R_{m}^{3}}
\end{aligned}
$$

Thus for one observation point, the magnetic field can be expressed with a matrix $\mathrm{A}$ as follows:

$$
\overrightarrow{\mathrm{H}_{\text {mod }}}\left(\mathrm{R}_{\mathrm{m}}, \mathrm{k}\right)=\mathrm{A}\left(\overrightarrow{\mathrm{R}}_{\mathrm{m}}, \mathrm{k}\right) \overrightarrow{\mathrm{M}}
$$

In this study, an optimization algorithm is used to solve the inverse problem: find equivalent dipoles from a near field cartography. One of the essential parameters is the fitness function. Among the different optimization functions the best results were obtained with the following expression which has to be minimized:

$$
\sum_{0}^{\mathrm{N}}\left|\overrightarrow{\mathrm{H}}-\overrightarrow{\mathrm{H}}_{\text {mod }}\right|^{2}
$$

where $\overrightarrow{\mathrm{H}}$ is the measured near field and $\overrightarrow{\mathrm{H}}$ mod is the field obtained from the radiation of the dipoles. $\mathrm{N}$ is the number of field points on the scanning plane.

Two different optimization methods have been combined: Genetic Algorithms and Pattern Search. It allowed us to increase performance by giving a better precision and by accelerating convergence. The genetic algorithm reproduces the principles of natural selection, meaning that the individuals with the best characteristics are those who have the biggest probability to transmit their genes to the next generation. Although the genetic algorithm normally almost independently from the starting point, from a certain degree of precision the convergence can take too much time [13]. The pattern search is used for increasing the reliability of the genetic algorithm, the output of the latter being the input of the former. The pattern search methods are a group of direct optimization methods that, does not require the calculation of any derivative of the objective function [13]. From an initial point in the space of the possible solutions of the problem, the algorithm draws a regular pattern around this point. Next, it calculates the value of the objective function on all the vertices of the pattern. Among all these points, the algorithm chooses the best one, which will be the initial point for the next iteration. If the algorithm does not find any point that is better than the initial one, it creates a new smaller pattern around this point in order to search to another, closer to it. When the size of the pattern is smaller than a certain limit the algorithm stops.

\section{B. Validation}

The parameters for one dipole are five: the three components of the magnetic moment and the two coordinates of the dipole on the plane of the screen. The frequency is $470 \mathrm{MHz}$. The generation number is 150 . The crossover probability and mutation probability are 0.8 and 0.4 respectively. The algorithm automatically increases the number of dipoles while the relative difference between the magnitude of the field obtained by the dipoles and the magnitude of field obtained by measurements remains above a threshold. In this example section the threshold 
has been fixed to $5 \%$. Table I shows the parameters of the set of equivalent dipoles. Near field cartographies are presented on figure 3. The magnetic field computed by the method of moment is shown on figure 3(b). The experimental approach gives the near field data (a) which is used to find the equivalent dipoles. The magnetic field predicted by the dipole is presented in (c). A rather good agreement between the numerical results obtained with the method of moment is observed. Screens $1,2,4,5$ are correctly modeled by one magnetic dipole while screen 3 can be replaced by two dipoles. The dipoles for screens $1,3,4,5$ have the same orientations than the moment of the loop. For the screen 2 the direction of the moment is slightly modified compared to the vertical direction. The magnitudes of the moments are proportional to the area of the apertures.

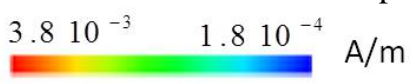

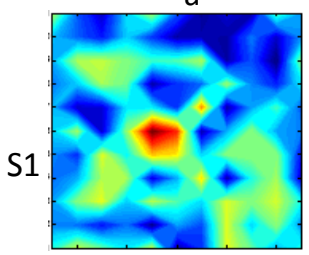

S2
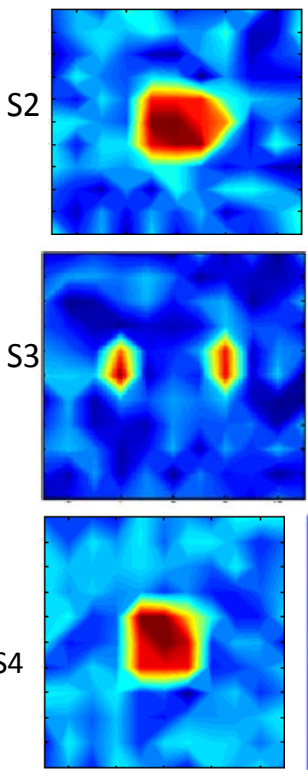

S5

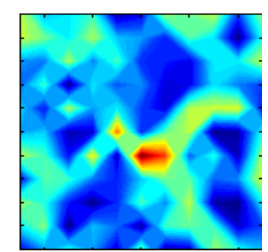

b
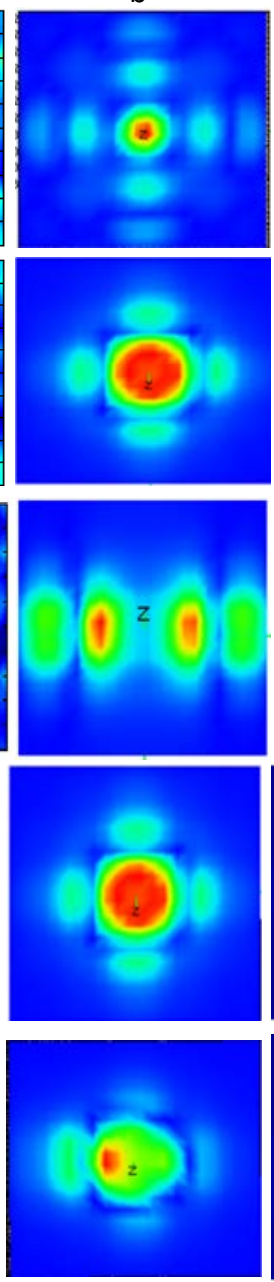
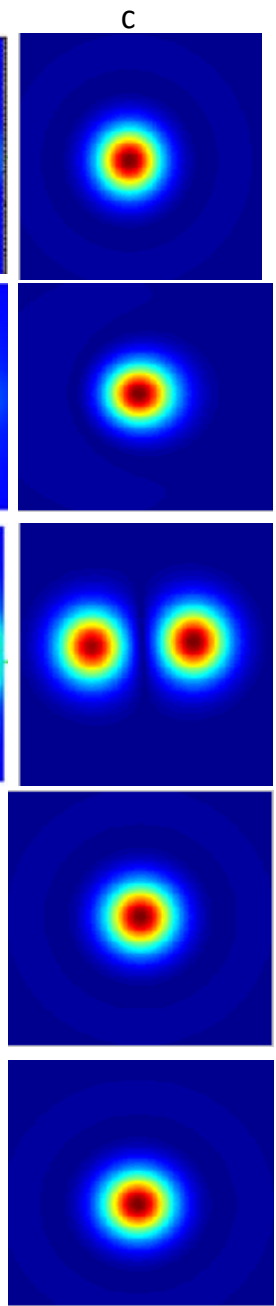

Fig. 3. 2D XY mapping of $\mathrm{H}_{\mathrm{z}}$ : experimental approach (a), numerical modeling (b) and inverse problem (c).

Results could be more accurate via implicating the cartography of the difference between (a) and (c) as shown in [9] or decreasing the threshold of 5\%.
TABLE I

PARAMETERS OF THE IDENTIFIED DIPOLES

\begin{tabular}{lccccc}
\hline Screen & $\mathbf{x}(\mathbf{m})$ & $\mathbf{Y}(\mathbf{m})$ & $\mathbf{M x}\left(\mathbf{A} \cdot \mathbf{m}^{2}\right)$ & $\mathbf{M y}\left(\mathbf{A} \cdot \mathbf{m}^{2}\right)$ & $\mathbf{M z}\left(\mathbf{A} \cdot \mathbf{m}^{2}\right)$ \\
\hline S1 & 0.0074 & 0.0079 & 0. & 0. & $9.3 \mathrm{e}-7$ \\
S2 & 0.0077 & 0.0083 & $2.6 \mathrm{e}-9$ & $1 . \mathrm{e}-7$ & $2.1 \mathrm{e}-6$ \\
S3 & 0.0037 & 0.0087 & 0. & 0. & $1.1 \mathrm{e}-7$ \\
& 0.0087 & 0.0085 & 0. & 0. & $4.2 \mathrm{e}-7$ \\
S4 & 0.0083 & 0.0083 & 0. & 0. & $1.7 \mathrm{e}-6$ \\
S5 & 0.0041 & 0.0067 & 0. & 0. & $1.9 \mathrm{e}-6$ \\
\hline
\end{tabular}

\section{Shielding effectiveness evaluation}

The shielding effectiveness of each structure at a frequency $470 \mathrm{MHz}$ and with height $\mathrm{z}=5 \mathrm{~mm}$ has been evaluated on the axis the loop (red axis in Figure 2) and a comparison between the results given by different approaches is shown in table II. The relative error about SE the inverse problem and the experimental approach is lower than $7 \%$.

TABLE II

SE OBTAINED WITH DIFFERENT APPROACHES

\begin{tabular}{cccc}
\hline Screen & $\begin{array}{c}\text { Experimental } \\
\text { approach }\end{array}$ & $\begin{array}{c}\text { Moment } \\
\text { method }\end{array}$ & $\begin{array}{c}\text { Inverse } \\
\text { problem }\end{array}$ \\
\hline S1 & 17.8 & 16.9 & 18.2 \\
S2 & 7.6 & 6.8 & 7.7 \\
S3 & 24.9 & 26.8 & 23.5 \\
S4 & 8.9 & 5.7 & 9.5 \\
S5 & 8.1 & 7.6 & 8.3 \\
\hline
\end{tabular}

The ability of this model to predict SE at a different height has been studied. The comparison between the results obtained with the method of moment and the dipoles is shown in figure 4 for $\mathrm{z}=10 \mathrm{~mm}$ with SE in decibels ( $\left.\mathrm{SE}_{\mathrm{db}}\right)$. The incident field is not constant (the study is performed in near field and not in far field). On the loop axis the incident field behaves like the inverse of the cube of the distance from the loop. Also the field created by a magnetic dipole has the same variation along the vertical axis (cube of the distance from the shield). With such dependence versus the distance it is easy to show that the $\mathrm{SE}$ values calculated at $\mathrm{z}=10 \mathrm{~mm}$ are several decibels greater than those calculated at $\mathrm{z}=5 \mathrm{~mm}$. The relative error about $\mathrm{SE}$ between the numerical simulation and the inverse resolution remains below 3\%. Although some differences indeed exist on the $\mathrm{H}_{\mathrm{z}}$ field cartographies over the whole scanning plane the values of SE in the center of the region evaluated by the method is rather close to the experimental one. It must be noted that the distribution of (a) and (b) in Fig.4 are different because the $\mathrm{z}$ component distribution is different but the magnitude of the magnetic field evaluated in the center of the region is close to the magnitude predicted by the method of moment $\left(\mathrm{H}_{\mathrm{z}}\right.$ is the smallest component) thus leading to close values of SE (which are deduced from the magnitudes of the fields).

The influence of the frequency on the shielding effectiveness was investigated. No significant effect was noticed for the range $[300 \mathrm{MHz}, 600 \mathrm{MHz}]$ around the center frequency which has been chosen for the identification. Figure 5 shows for the two screens S2 and S3 a comparison between the field predicted by the method of moment and the field resulting from the equivalent model. The relative error about SE remains below $4 \%$. 


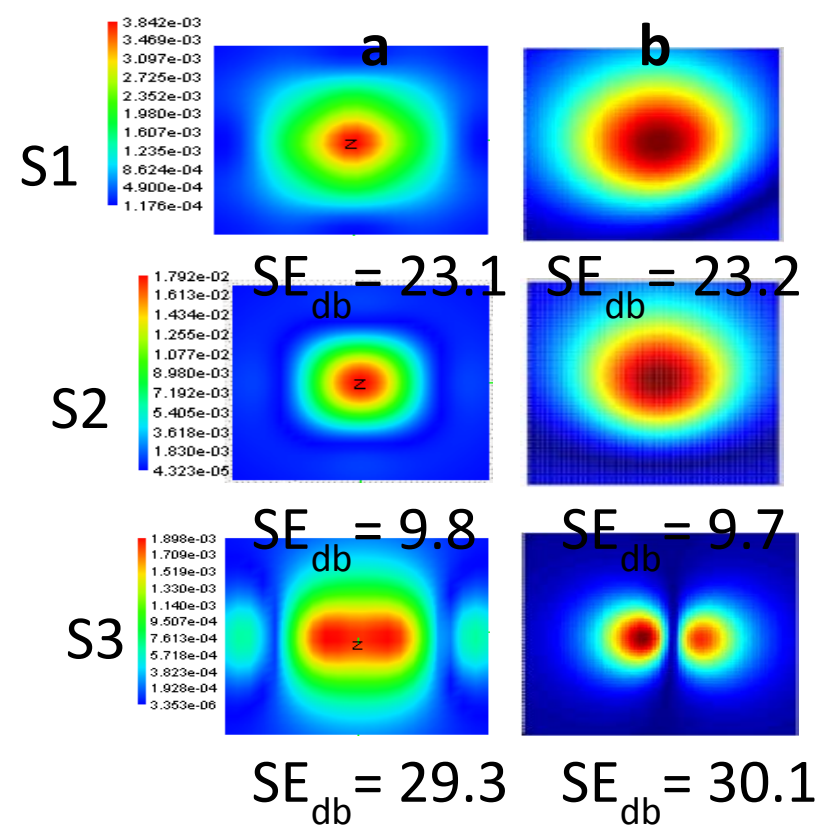

Fig. 4. $\mathrm{H}_{\mathrm{z}}$ obtained by simulation (a) and inverse problem approach (b)

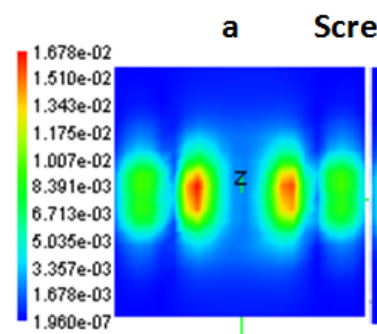

creen 3
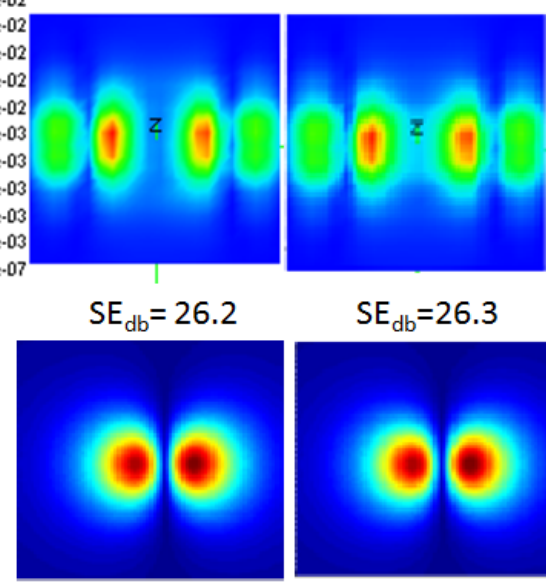

Method of moment

$\mathrm{SE}_{\mathrm{db}}=26.3$

$S E_{d b}=26.4$

a Screen 2 b
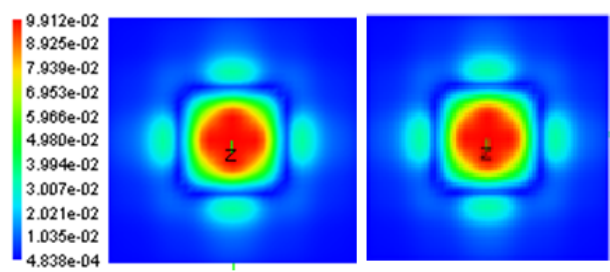

Method

of moment

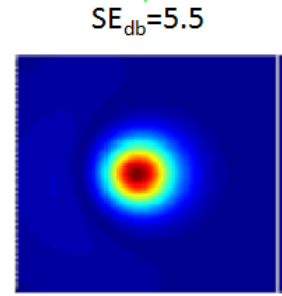

$\mathrm{SE}_{\mathrm{db}}=5.7$

$$
\mathrm{SE}_{\mathrm{db}}=5.6
$$

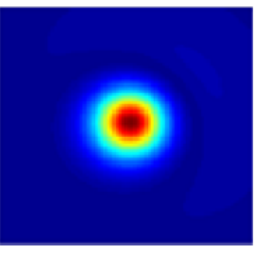

Inverse problem

Fig. 5. $\mathrm{H}_{\mathrm{z}}$ cartography for $300 \mathrm{MHz}$ (a) and $600 \mathrm{MHz}$ (b)

\section{CONCLUSION}

In this work an inverse problem based resolution was proposed to find an equivalent model based on magnetic dipoles of different perforated screen. A comparison of the results predicted by the dipoles with those obtained with a full wave model and measurements has demonstrated the validity of this approach. The work shows that a small number of dipoles is sufficient to represent the field radiated through arrays of apertures and to predict the shielding effectiveness in a simple way for a range of frequencies. Such a set of dipoles can be directly incorporated in a 3D mesh method to represent a wall of apertures avoiding a fine mesh around the perforations. Also the method demonstrates that a power electronic device with perforated shields can be easily represented by a few number of dipoles. This is of interest for complex EMC problems involving embedded power supplies in automotive applications for example.

\section{REFERENCES}

[1] S. Celozzi, R. Araneo, G. Lovat, "Electromagnetic Shielding", John Wiley and Sons, IEEE Press, 2008.

[2] L. Sandrolini, A. Massarini, U. Reggiani, Transform Method for Calculating Low-Frequency Shielding Effectiveness of Planar Linear Multilayered Shields, IEEE Transactions on Magnetics, vol.36, n6, 2000, pp 3910-3919.

[3] Z. B. Zhao, X. Cui, L. Li, B. Zhang, Analysis of the Shielding Effectiveness of Rectangular Enclosure of Metal Structures With Apertures Above Ground Plane, IEEE Transactions on Magnetics., vol. 41, n5, 2005, pp 1892-1895.

[4] W. P. Carpes, G. S. Ferreira, A. Raizer, L. Pichon, and A. Razek, "TLM and FEM methods applied in the analysis of electromagnetic coupling," IEEE Transactions on Magnetics., vol. 36, no. 4, pp. 982-985, Jul. 2000.

[5] K. J. W. Pluk , G. De Gersem , J. W. Jansen , E. A. Lomonova, Field Calculations for Magnetic Shielding: Fourier Modeling Extended With Mode-Matching Technique Applied on a Shield With Finite Dimensions, IEEE Transactions on. Magnetics., vol. 49, n5, 2013 pp 1593-1596.

[6] R. Araneo, G. Lovat, S. Celozzi, "Shielding Effectiveness of Periodic Screens Against Finite High-Impedance Near-Field Sources” IEEE Transactions on Electromagnetic Compatibility,, vol.53, no.3, pp.706716, Aug. 2011.

[7] G. Lovat, R. Araneo, S. Celozzi, "Dipole Excitation of Periodic Metallic Structures", Antennas and Propagation, IEEE Transactions on, vol. 59, $\mathrm{n}^{\circ} 6$, 2011, pp 2178-2187.

[8] S. Criel, L. Martens, D. De Zutter, “Near- and far-field characterization of perforated screens: theoretical and experimental study of proposed definitions for the shielding performance" Electromagnetic Compatibility, IEEE International Symposium on, 22-26 Aug 1994.

[9] S. Saidi, J. Ben HadjSlama, "A Near-Field Technique Based on PZMI, GA, and ANN: Application to Power Electronics Systems”, IEEE Trans. Electromagnetic Compatibility., vol. 56, no. 4, 2014, pp. 784-791.

[10] L. Beghou, B. Liu, L. Pichon, F. Costa, "Synthesis of Equivalent 3-D Models from Near Field Measurements- Application to the EMC of Power Printed Circuit Boards”, IEEE Transactions on Magnetics, vol.45, no.3, pp.1650,1653, March 2009.

[11] L. Beghou, L. Pichon, F. Costa, "Detection of Electromagnetic Radiations Sources at the Switching Time Scale Using an Inverse Problem-Based Resolution Method-Application to Power Electronic Circuits”, IEEE Transactions on Electromagnetic Compatibility., vol. 57, no. 1, 2015, pp. 52-59.

[12] Z. Michalewicz, Genetic Algorithms $\square$ Data Structures Evolution Programs, 3rd ed. New York: Springer, 1996, revised and extended edition.

[13] Abramson, Mark A. Pattern Search Filter Algorithms for Mixed Variable General Constrained Optimization Problems. Ph.D. Thesis, Department of Computational and Applied Mathematics, Rice University, August 2002. 